\section{(6) OPEN ACCESS}

\title{
Arthroscopic partial meniscectomy versus placebo surgery for a degenerative meniscus tear: a 2-year follow-up of the randomised controlled trial
}

\author{
Raine Sihvonen, ${ }_{1}^{1}$ Mika Paavola, ${ }^{2}$ Antti Malmivaara, ${ }^{3}$ Ari Itälä, ${ }_{1}^{4}$ Antti Joukainen, ${ }^{5}$ \\ Heikki Nurmi, ${ }^{6}$ Juha Kalske, ${ }^{2}$ Anna Ikonen, ${ }^{2}$ Timo Järvelä, ${ }^{7}$ Tero A H Järvinen, ${ }^{8}$ \\ Kari Kanto, ${ }^{1}$ Janne Karhunen, ${ }^{2}$ Jani Knifsund, ${ }^{4}$ Heikki Kröger, ${ }^{5}$ Tommi Kääriäinen, ${ }^{5}$ \\ Janne Lehtinen, ${ }^{1}$ Jukka Nyrhinen, ${ }^{6}$ Juha Paloneva, ${ }^{6}$ Outi Päiväniemi, ${ }^{1}$ Marko Raivio, ${ }^{1}$ \\ Janne Sahlman, ${ }^{5}$ Roope Sarvilinna, ${ }^{2}$ Sikri Tukiainen, ${ }^{2}$ Ville-Valtteri Välimäki, ${ }^{2}$ \\ Ville Äärimaa, ${ }^{4}$ Pirjo Toivonen, ${ }^{9}$ Teppo L N Järvinen, ${ }^{9}$ The FIDELITY (Finnish \\ Degenerative Meniscal Lesion Study) Investigators
}

For numbered affiliations see end of article.

\section{Correspondence to}

Professor Teppo L N Järvinen, Department of Orthopaedics and Traumatology, University of Helsinki and Helsinki University Hospital, Töölö Hospital, Topeliuksenkatu 5, Helsinki 00260, Finland:

teppo.jarvinen@helsinki.fi

Received 19 January 2017 Revised 3 April 2017 Accepted 13 April 2017 Published Online First 18 May 2017

\section{Linked}

- http://dx.doi.org/10.1136/ annrheumdis-2017-211664

\section{CrossMark}

To cite: Sihvonen $R$, Paavola M, Malmivaara A, et al. Ann Rheum Dis 2018;77:188-195.

\section{ABSTRACT}

Objective To assess if arthroscopic partial

meniscectomy (APM) is superior to placebo surgery in the treatment of patients with degenerative tear of the medial meniscus.

Methods In this multicentre, randomised, participantblinded and outcome assessor-blinded, placebosurgery controlled trial, 146 adults, aged 35-65 years, with knee symptoms consistent with degenerative medial meniscus tear and no knee osteoarthritis were randomised to APM or placebo surgery. The primary outcome was the between-group difference in the change from baseline in the Western Ontario Meniscal Evaluation Tool (WOMET) and Lysholm knee scores and knee pain after exercise at 24 months after surgery. Secondary outcomes included the frequency of unblinding of the treatment-group allocation, participants' satisfaction, impression of change, return to normal activities, the incidence of serious adverse events and the presence of meniscal symptoms in clinical examination. Two subgroup analyses, assessing the outcome on those with mechanical symptoms and those with unstable meniscus tears, were also carried out.

Results In the intention-to-treat analysis, there were no significant between-group differences in the mean changes from baseline to 24 months in WOMET score: 27.3 in the APM group as compared with 31.6 in the placebo-surgery group (between-group difference, $-4.3 ; 95 \% \mathrm{Cl},-11.3$ to 2.6); Lysholm knee score: 23.1 and 26.3 , respectively $(-3.2 ;-8.9$ to 2.4$)$ or knee pain after exercise, 3.5 and 3.9 , respectively $(-0.4 ;-1.3$ to 0.5 ). There were no statistically significant differences between the two groups in any of the secondary outcomes or within the analysed subgroups.

Conclusions In this 2-year follow-up of patients without knee osteoarthritis but with symptoms of a degenerative medial meniscus tear, the outcomes after APM were no better than those after placebo surgery. No evidence could be found to support the prevailing ideas that patients with presence of mechanical symptoms or certain meniscus tear characteristics or those who have failed initial conservative treatment are more likely to benefit from APM.

\section{INTRODUCTION}

Arthroscopic partial meniscectomy (APM) is one of the most common orthopaedic operations, ${ }^{1}$ with an incidence that has increased steadily from $1990 \mathrm{~s}$ until late 2010s. ${ }^{2-5}$ Most APMs are carried out in middle-aged and older patients with knee symptoms and degenerative knee disease. ${ }^{1}{ }^{2}$ Several recent meta-analyses based on randomised controlled trials (RCTs) have failed to show a treatment-benefit of APM over conservative treatment or placebo surgery for these patients. ${ }^{6-10}$

Aligned with the evidence, most guidelines and expert opinion now refrain from recommending APM as the first-line treatment for patients with a degenerative meniscus tear, but still advocate surgery after a failed attempt of conservative treatment. ${ }^{11-16}$ Such recommendations rest on three issues: generally favourable clinical experience, some before-after studies on patients undergoing APM due to persisting symptoms despite conservative treatment ${ }^{17} 18$ and particularly the evidence from three $\mathrm{RCTs}^{19-21}$ in which one-third of participants initially allocated to non-surgical treatment opted for crossing over to APM due to persisting knee symptoms or insufficient improvement. After undergoing APM, participants achieved similar outcomes compared with those initially assigned to surgery and those responding favourably to initial non-surgical/conservative treatment. ${ }^{19-21}$ These findings have been interpreted as evidence that APM should be performed after failed conservative treatment. ${ }^{22}$ Although such hypotheses might well be true, an alternative accounting can explain the number of crossovers and the beneficial treatment effects of surgery after failed conservative treatment: lack of blinding (participants' knowledge of not having undergone surgery) may drive conservatively treated patients to request surgery and also make them feel more content with the outcome once having undergone surgery. ${ }^{23} 24$

In addition to patients failing to improve after conservative treatment, other subgroups considered to benefit from APM are those with so-called 'mechanical symptoms ${ }^{\text {,5-28 }}$ or those with 'unstable' meniscal tear. ${ }^{15} 1728$ 


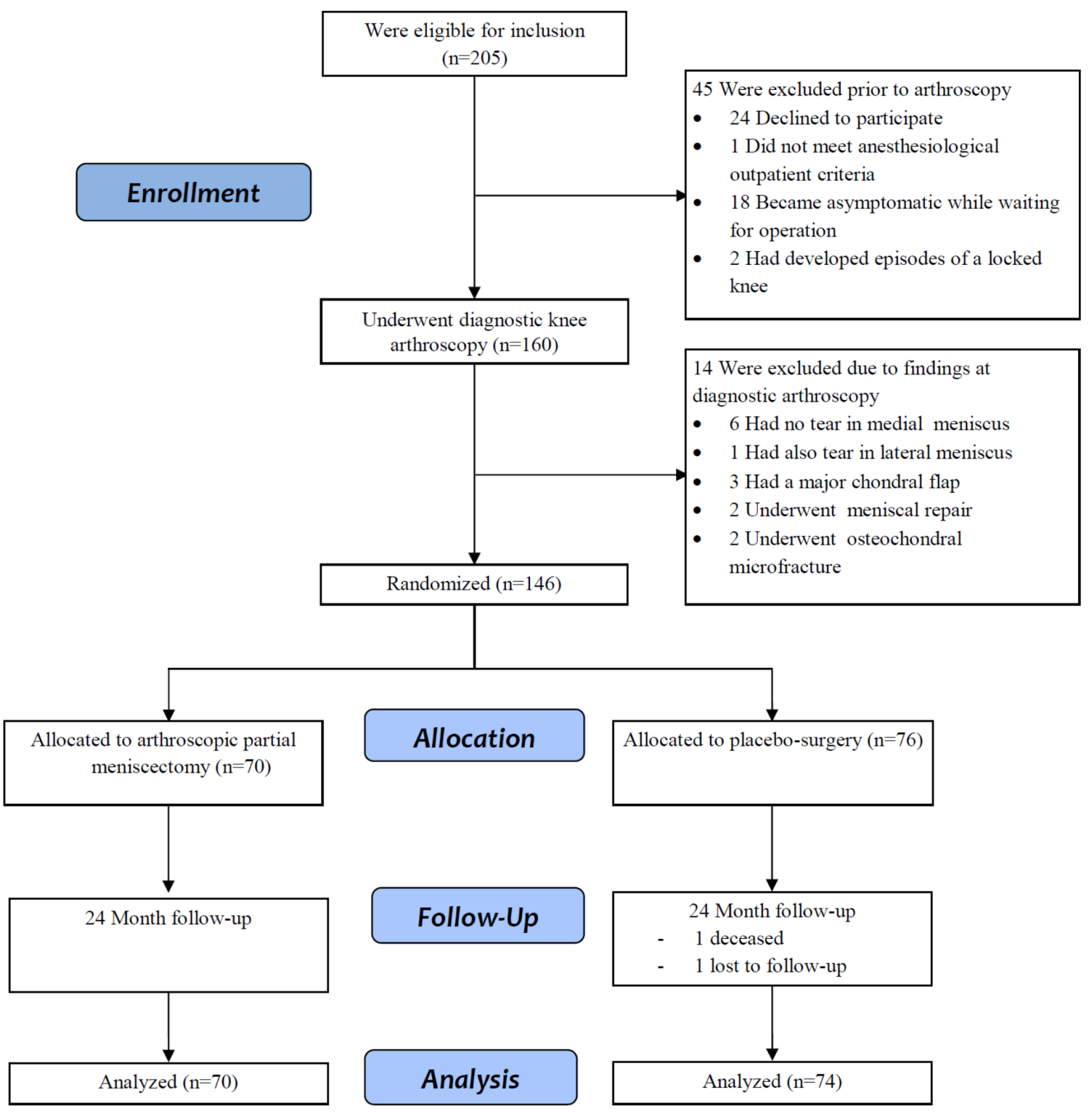

Figure 1 Participant enrolment flow diagram.

Accordingly, the aim of this extension of our recently published Finnish Degenerative Meniscal Lesion Study (FIDELITY) trial ${ }^{29}$ was twofold: (a) to assess if APM is superior over placebo surgery over the course of 24-month follow-up determined using patient relevant outcomes, the frequency of unblinding of the treatment-group allocation and clinical examination of the knee and (b) to assess whether our data corroborates or refutes common assertions regarding existence of subgroups of patients likely to benefit from APM.

\section{MATERIALS AND METHODS}

We conducted a multicentre, randomised, participant-blinded and outcome assessor-blinded, placebo-surgery controlled efficacy trial involving participants aged 35-65 years with knee symptoms over 3 months, consistent with degenerative medial meniscus tear and unresponsive to conventional conservative treatment and no clinical ${ }^{30}$ or radiographic (Kellgren-Lawrence grade $\leq 1)^{31}$ knee osteoarthritis. The study took place in five orthopaedic centres in Finland during the period from December 2007 through March 2014. All patients had a suspicion of a meniscus tear based on symptoms and clinical tests, a tear that was later verified on both MRI and knee arthroscopy. Patients with an obvious trauma-induced onset of symptoms or with a recent history of a locked knee were excluded from the trial. On entering the study, participants were informed that they would be allowed to consider a reoperation 6 months or later after the procedure if they did not have adequate relief of symptoms.

Participants first underwent diagnostic knee arthroscopy and then (during the same operation) were assigned to APM or placebo surgery. For the randomisation, the sequentially numbered, opaque, sealed envelopes were prepared by a statistician. Randomisation was performed in a 1:1 ratio with a block size of 4 , and with stratification according to study site, age (35-50 or 51-65 years), sex and the absence or presence of minor degenerative changes on a radiograph (Kellgren-Lawrence grade 0 or 1 , respectively).

The participants, all caregivers and those assessing the outcomes were blinded to the treatment assignment. Participants were followed-up by questionnaires at $2,6,12$ and 24 months. At the 24-month follow-up, all participants were also clinically examined by an independent orthopaedic surgeon unaware of the treatment allocation. Standardised clinical examination included clinical meniscal tests ${ }^{32}:$ McMurray test,${ }^{33}$ pain provoked by joint line palpation and pain provoked by forced 
flexion and varus. Also, range of knee motion, knee crepitus, bony enlargement, effusion, location of pain at palpation and knee stability was recorded.

The study was registered at ClinicalTrials.gov (NCT00549172). We have described the design ${ }^{34}$ and published the 12-month results $^{29}$ of the trial previously. The protocol was approved by the institutional review board of the Pirkanmaa Hospital District ( $R$ 06157). The study was conducted in accordance with the Declaration of Helsinki. All participants gave written informed consent.

\section{Interventions}

Arthroscopic evaluation included recording the presence of intra-articular pathology (meniscus tears, loose bodies and characterisation of chondral lesions of both tibiofemoral and patellofemoral chondral surfaces) according to the International Cartilage Repair Society cartilage injury classification scale ${ }^{35}$ and the International Society of Arthroscopy, Knee Surgery and Orthopaedic Sports Medicine classification of meniscal tears. ${ }^{36}$

During the APM, the damaged and loose parts of the meniscus were removed with the use of arthroscopic instruments until solid meniscal tissue was reached with preservation of as much of the meniscus as possible. No other surgical procedure was performed. For the placebo surgery, APM was simulated to mimic the sensations and sounds of a true APM. The participants were also kept in the operating room for the amount of time required to perform an actual APM.

In both the APM and the placebo-surgery groups, postoperative care was delivered according to a standardised protocol specifying that all participants receive the same walking aids and instructions for the same graduated home-based exercise programme.

\section{Outcomes}

Primary outcomes were the change in Western Ontario Meniscal Evaluation Tool (WOMET), the Lysholm knee score and pain after exercise from baseline to 24 months after surgery. The WOMET $^{37}$ is a meniscus-specific health-related quality-of-life instrument, validated especially for patients with a degenerative meniscal tear. ${ }^{38}$ The Lysholm knee score is a validated, condition-specific outcome measure. ${ }^{39} 40$ WOMET and Lysholm scores each range from 0 to 100 , with 0 indicating the most severe symptoms and 100 the absence of symptoms. Knee pain (during the preceding week) was assessed on an 11-point numerical rating scale ranging from 0 (no pain) to 10 (extreme pain).

As a secondary outcome, the frequency of patients in the two treatment groups who did not have adequate relief of symptoms and whose treatment-group allocation was therefore unblinded was determined. Participants were also asked to respond to the following questions: "Are you satisfied with your knee at present?" and "Is your knee better than before the intervention?" on a 5 -point Likert scale. As before, ${ }^{41}$ the responses "very satisfied' or 'satisfied' were categorised as satisfied, while responses 'neither satisfied nor dissatisfied', 'dissatisfied' and 'very dissatisfied' were categorised as dissatisfied. Similar to satisfaction, the responses 'much better' and 'better' were considered to indicate improvement, while responses 'unchanged', 'worse' or 'much worse' were deemed not improved. Serious adverse events were registered. In addition, the participants were asked whether or not they were able to return to their previous activities. Finally, the frequency of participants with a positive meniscus test at clinical examination was assessed.

APM was also compared with placebo surgery within two subgroups of participants, those with mechanical symptoms of
Table 1 Baseline characteristics of the participants allocated to APM or placebo surgery. Values are numbers (percentages), means \pm SD or medians (ranges)

\begin{tabular}{|c|c|c|}
\hline & $\begin{array}{l}\text { APM } \\
(\mathrm{n}=70)\end{array}$ & $\begin{array}{l}\text { Placebo surgery } \\
(n=76)\end{array}$ \\
\hline \multicolumn{3}{|l|}{ Sex } \\
\hline Female & $28(40)$ & $29(38)$ \\
\hline Male & $42(60)$ & $47(62)$ \\
\hline Age (years) & $52.1 \pm 6.9$ & $52.0 \pm 7.2$ \\
\hline Body mass index $\left(\mathrm{kg} / \mathrm{m}^{2}\right)$ & $26.9 \pm 4.0$ & $27.9 \pm 4.0$ \\
\hline Duration of symptoms (months) & $10(3-50)$ & $10(3-47)$ \\
\hline \multicolumn{3}{|l|}{ Kellgren-Lawrence grade* } \\
\hline 0 & $35(50)$ & $36(47)$ \\
\hline 1 & $35(50)$ & $40(53)$ \\
\hline \multicolumn{3}{|l|}{ Meniscal tests } \\
\hline Positive McMurray test† & $16(23)$ & $15(20)$ \\
\hline Pain provoked by forced flexion and compression & $50(71)$ & $59(78)$ \\
\hline Pain provoked by palpation at the joint line & $63(90)$ & $74(97)$ \\
\hline Symptoms of catching or locking & $32(46)$ & $37(49)$ \\
\hline Unstable tear at knee arthroscopy $\ddagger$ & $34(49)$ & $41(54)$ \\
\hline WOMET score§ & $56.4 \pm 17.3$ & $52.8 \pm 18.1$ \\
\hline Lysholm scoref & $60.2 \pm 14.7$ & $60.1 \pm 14.6$ \\
\hline Pain after exercise (VAS) ${ }^{* *}$ & $5.8 \pm 2.0$ & $6.1 \pm 2.0$ \\
\hline
\end{tabular}

${ }^{*}$ The Kellgren-Lawrence scale is a radiographic classification of the severity of knee osteoarthritis. Grade 0 denotes no abnormalities and grade 1 denotes minor degenerative changes (doubtful narrowing of the joint space or possible osteophytic lipping).

tResults of a McMurray test are positive if a 'click' over the medial tibiofemoral joint line is felt by the examiner during flexion and extension of the knee under varus stress.

‡Longitudinal, bucket handle or flap tear at arthroscopy.

$\S$ The WOMET contains 16 items addressing three domains: 9 items addressing physical symptoms; 4 items addressing disabilities with regard to sports, recreation, work and lifestyle and 3 items addressing emotions. The score indicates the percentage of a normal score; therefore, 100 is the best possible score and 0 is the worst possible score.

IThe Lysholm knee score is based on an eight-item questionnaire designed to evaluate knee function and symptoms in activities of daily living. Scores range from 0 to 100; higher scores indicate less severe symptoms.

${ }^{*}$ Knee pain after exercise (during the preceding week) was assessed on a rating scale of $0-10$, with 0 denoting no pain and 10 denoting extreme pain. APM, arthroscopic partial meniscectomy; WOMET, Western Ontario Meniscal Evaluation Tool; VAS, visual analogue scale.

the knee and those with unstable meniscus tear. The presence of mechanical symptoms was assessed using the locking domain question of the Lysholm knee score. ${ }^{39}$ In brief, we asked patients to choose one out of five following responses that best reflected the status of their knee: i) no locking or catching, ii) catching sensations but no locking, iii) occasional locking, iv) frequent locking or v) locked at present. Meniscus tears with longitudinal tear pattern, bucket handle tear or flap were determined as unstable, whereas radial, horizontal and complex were determined as stable. ${ }^{13}$

\section{Patient involvement}

There was no active patient involvement in the design of the study, in the recruitment to or conduct of the study. However, one of the main outcome measures (the WOMET) was initially developed with a patient-centred approach: the items included in the final version of the questionnaire were those identified by patients to impact most significantly on their quality of life. ${ }^{37}$ The results of this RCT will be conveyed to the participants in lay language in a pamphlet distributed by mail after the 5-year follow-up. 
Table 2 Primary outcomes of the trial at 24-month follow-up. Values are means with $95 \% \mathrm{Cls}$

\begin{tabular}{|c|c|c|c|c|c|}
\hline \multirow[t]{2}{*}{ Primary outcomes } & \multirow[t]{2}{*}{ APM $(n=70)$} & \multirow[t]{2}{*}{$\begin{array}{l}\text { Placebo surgery } \\
(n=74)\end{array}$} & \multicolumn{2}{|c|}{ Improvement from baseline } & \multirow[t]{2}{*}{$\begin{array}{l}\text { Between-Group Difference in } \\
\text { Improvement from Baseline }\end{array}$} \\
\hline & & & APM & Placebosurgery & \\
\hline \multicolumn{6}{|l|}{ Unadjusted } \\
\hline WOMET score* & 83.7 (79.0 to 88.3$)$ & 83.9 (79.9 to 87.9$)$ & $27.3(22.1$ to 32.4$)$ & 31.6 (26.9 to 36.3$)$ & $-4.3(-11.3$ to 2.6$)$ \\
\hline Lysholm knee scoret & 83.3 (79.5 to 87.1$)$ & 85.9 (83.1 to 88.8$)$ & 23.1 (18.8 to 27.4$)$ & 26.3 (22.6 to 30.0$)$ & $-3.2(-8.9$ to 2.4$)$ \\
\hline Pain after exercise $\ddagger$ & 2.3 (1.7 to 2.9$)$ & 2.3 (1.7 to 2.9$)$ & 3.5 (2.8 to 4.2$)$ & 3.9 (3.3 to 4.6$)$ & $-0.4(-1.3$ to 0.5$)$ \\
\hline \multicolumn{6}{|l|}{ Adjusted§ } \\
\hline WOMET score & 80.9 (75.4 to 86.5$)$ & 86.1 (80.5 to 91.8 ) & 26.6 (21.1 to 32.2$)$ & $31.8(26.2$ to 37.5$)$ & $-5.2(-13.1$ to 2.7$)$ \\
\hline Lysholm knee score & 82.2 (78.2 to 86.3$)$ & 86.5 (82.3 to 90.6$)$ & 22.3 (18.3 to 26.3$)$ & 26.6 (22.4 to 30.7$)$ & $-4.3(-10.0$ to 1.5$)$ \\
\hline Pain after exercise & 2.3 (1.5 to 3.1$)$ & 1.9 (1.1 to 2.7$)$ & 3.7 (2.9 to 4.5$)$ & 4.1 (3.3 to 4.9$)$ & $-0.4(-1.5$ to 0.7$)$ \\
\hline
\end{tabular}

*The WOMET contains 16 items addressing three domains: 9 items addressing physical symptoms; 4 items addressing disabilities with regard to sports, recreation, work and lifestyle and 3 items addressing emotions. The score indicates the percentage of a normal score; therefore, 100 is the best possible score and 0 is the worst possible score. †The Lysholm knee score is based on an eight-item questionnaire designed to evaluate knee function and symptoms in activities of daily living. Scores range from 0 to 100 ; higher scores indicate less severe symptoms.

$\ddagger$ Knee pain after exercise (during the preceding week) was assessed on a rating scale of $0-10$, with 0 denoting no pain and 10 denoting extreme pain.

$\S$ Values are adjusted with the baseline score, study site, age, sex and the absence or presence of minor degenerative changes on a radiograph (Kellgren-Lawrence grade 0 or 1 , respectively).

APM, arthroscopic partial meniscectomy; WOMET, Western Ontario Meniscal Evaluation Tool.

\section{Statistical methods}

The trial was designed to ascertain whether APM is superior to placebo surgery in treating patients with knee pain and a degenerative meniscus tear. Baseline characteristics were analysed with the use of descriptive statistics. For the primary analysis, the change in each score (mean with $95 \% \mathrm{CI}$ ) from baseline to 24 months was compared between the two study groups. This analysis was also performed after adjustment for the baseline score and for the stratifying variables used for randomisation. The study was powered to detect a minimal clinically important improvement in the WOMET and Lysholm scores (described as improvements of at least 15.5 and 11.5 points, respectively) and in the score for knee pain after exercise (improvement of at least 2.0 points). ${ }^{34}$ For the secondary analyses, the frequency of assessed outcomes were compared between the two groups. Two subgroup analyses were carried out, for those with mechanical symptoms and for those with unstable meniscus tear; $\mathrm{p}$ values for interaction were calculated for the subgroup analyses.

A Student's t-test and non-parametric test (Mann-Whitney U test) were used to compare continuous variables (normally distributed and not normally distributed, respectively) between the groups, and Fisher's exact test was used with binomial and categorical variables. All statistical analyses were performed on an intention-to-treat basis; as the frequency of crossover was low, no per-protocol analysis was performed. A p value of 0.05 was considered to indicate statistical significance. SPSS Statistics, V.23 (IBM), was used for all statistical analyses.

\section{RESULTS}

The flow chart of the trial is shown in figure 1. Of the 205 eligible patients, 146 underwent randomisation; 70 were assigned to APM and 76 to placebo surgery. The baseline characteristics of the two groups were similar. On average, half of the participants in both groups reported mechanical symptoms preoperatively. There were 34 participants with a tear morphology defined as 'unstable' in the APM group and 41 in the placebo-surgery group (table 1). There were 24 patients who were eligible but declined to participate in the study. They were similar to those who underwent randomisation with respect to age, sex and body mass index at baseline, and all of them underwent arthroscopic partial meniscectomy. At the 24-month follow-up, two participants were lost to follow-up (one not responding to contact attempts and one deceased), both from the placebo-surgery group.

Both groups showed a marked improvement in all primary outcomes. However, the difference between the two groups did not reach statistical significance and 95\% CIs excluded clinically relevant effect in any of the three primary outcomes over the course of the 24-month follow-up (table 2 and figure 2). Five participants $(7.1 \%)$ in the APM group and seven $(9.2 \%)$ in the placebo-surgery group complained of symptoms severe enough to result in the unblinding of the treatment-group allocation $(p=0.767)$. Most of the participants, in both groups, were satisfied and reported improvement with no statistically significant difference between the two treatment groups. One participant in the APM group had a serious adverse event (a knee infection 4 months after the initial operation). No between-group difference was observed in the participants' frequency in returning to normal activity level or in the frequency of mechanical symptoms. No statistically significant difference was found between the two groups in the meniscal tests during clinical examination either (table 3 ). The outcome of the patients who declined to participate ( $n=17$, five lost to follow-up) were similar with those randomised, excluding the change in WOMET score (SD), which was greater for those declined $(43.2 \pm 22.4)$ as compared with those randomised $(29.5 \pm 21.1)$ with a between-group difference -13.7 (95\% CI -25.6 to -2.9$)$.

In the two subgroup analyses, one assessing the effect of preoperative mechanical symptoms and the other the effect of unstable tear on the treatment outcome, there was no difference in any of the primary or secondary outcomes between the APM and placebo-surgery groups (tables 4 and 5).

\section{DISCUSSION}

In this extension of the FIDELITY trial, ${ }^{29}$ we found no statistically significant difference between the APM and placebo surgery for symptomatic patients with a degenerative meniscus tear and no osteoarthritis (OA) in any of the used outcome measures over the course of 24-month follow-up. No evidence could be found to support the prevailing ideas that patients with presence of mechanical symptoms or certain meniscus tear characteristics or those who failed initial conservative treatment are more likely to benefit from APM. 

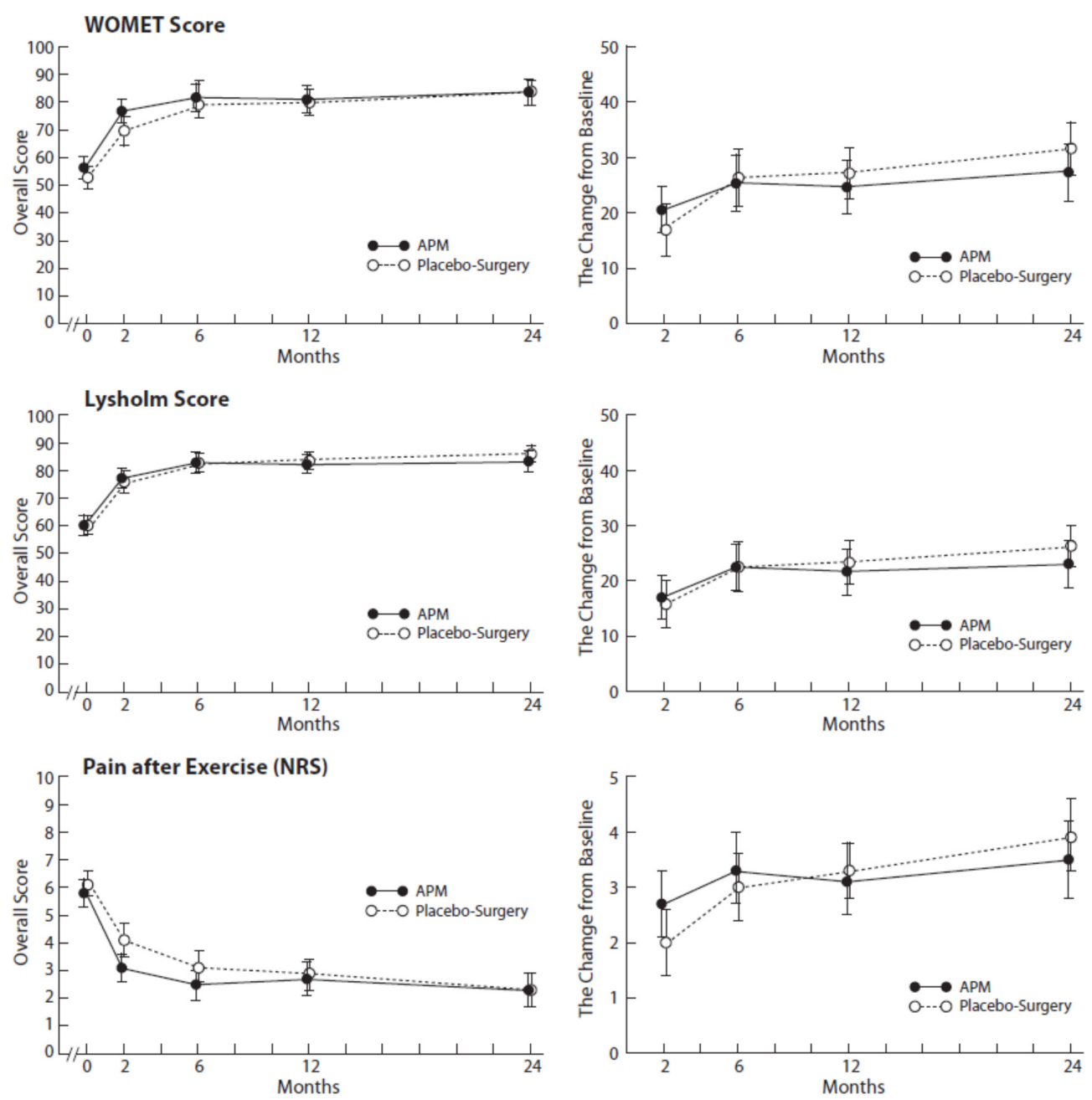

Figure 2 Mean values with $95 \% \mathrm{Cls}$ in all three primary scores during the 24-month follow-up for both groups. APM, arthroscopic partial meniscectomy; NRS, numerical rating scale; WOMET, Western Ontario Meniscal Evaluation Tool.

The strengths of the FIDELITY trial have been elaborated in detail previously. ${ }^{29} 34$ In brief, our study was a multicentre, randomised, placebo-controlled efficacy trial with a 2-year

\begin{tabular}{|c|c|c|c|}
\hline Outcome & $\begin{array}{l}\text { APM } \\
(n=70)\end{array}$ & $\begin{array}{l}\text { Placebo surgery } \\
(n=74)\end{array}$ & $P$ Value \\
\hline Satisfied patients & $54(77.1)$ & $58(78.4)$ & 1.000 \\
\hline Improved patients & $61(87.1)$ & $63(85.1)$ & 0.812 \\
\hline Treatment-group unblinding & $5(7.1)$ & $7(9.2)$ & 0.767 \\
\hline Reoperations & $4(5.7)$ & $7(9.2)$ & 0.537 \\
\hline Arthroscopy & $2(2.9)$ & $6(7.9)$ & 0.279 \\
\hline HTO/TKR & $2(2.9)$ & $1(1.3)$ & 0.607 \\
\hline Returned to normal activities & $50(72.5)$ & $58(78.4)$ & 0.442 \\
\hline Serious adverse events & $1(1.4)$ & 0 & 0.479 \\
\hline Mechanical symptoms & $18(25.7)$ & $15(20.3)$ & 0.552 \\
\hline \multicolumn{4}{|l|}{ Meniscal tests } \\
\hline Positive McMurray test & $6(8.6)$ & $5(6.8)$ & 0.760 \\
\hline $\begin{array}{l}\text { Pain provoked by forced flexion and } \\
\text { compression }\end{array}$ & $8(11.4)$ & $10(13.5)$ & 0.803 \\
\hline $\begin{array}{l}\text { Pain provoked by palpation at the } \\
\text { joint line }\end{array}$ & $22(31.4)$ & $21(28.8)$ & 0.855 \\
\hline At least one positive meniscal test & $26(37.1)$ & $25(33.8)$ & 0.729 \\
\hline
\end{tabular}

HTO, high tibial osteotomy; TKR, total knee replacement. follow-up. Controlling for the possible placebo effects of surgery requires that besides participants, all caregivers and outcome assessors are blinded to the treatment allocation. ${ }^{42}$ The use of multiple validated outcomes covering many different possible symptoms related to degenerative knee and meniscus tear can also be considered strength of this trial.

There are also some limitations worth discussing. We excluded patients with a truly 'traumatic' onset of symptoms, so our results are only directly applicable to patients with non-traumatic meniscus tears. Obviously, the concepts 'degenerative' or 'traumatic' in the context of meniscal injuries are very vague by nature. In this trial, all patients with sudden injuries related to their own voluntary muscle activities (such as kneeling, bending or kicking) and patients with a minor twisting of the knee were included. In essence, our criteria for labelling a tear as 'traumatic' required a more substantial event, such as falling from a chair, stairs or bicycle, or slipping on ice. In this context, to our knowledge, the only study specifically testing the assumption that meniscal tear outcomes would be any better for those with a traumatic onset of symptoms than for those without does not support such hypothesis. ${ }^{43}$ Moreover, a very recent study showed that patients with traumatic meniscal tears do not experience greater improvements in patient-reported outcomes after APM than patients with degenerative tears. ${ }^{44}$

The generalisability of the FIDELITY trial has been questioned. ${ }^{25} 4546$ Although the design of the FIDELITY has been elaborated in detail previously, ${ }^{34}$ it is worth reasserting that it was 
Table 4 Primary and secondary outcomes at 24-month follow-up for the subgroup of patients with mechanical symptoms at baseline. Values are means with $95 \% \mathrm{Cls}$ and numbers (percentage)

\begin{tabular}{|c|c|c|c|c|c|}
\hline \multirow[b]{2}{*}{ Primary outcomes } & \multirow[t]{2}{*}{ APM $(n=32)$} & \multirow[t]{2}{*}{$\begin{array}{l}\text { Placebo } \\
\text { surgery }(n=37)\end{array}$} & \multicolumn{2}{|c|}{ Improvement from baseline } & \multirow[t]{2}{*}{$\begin{array}{l}\text { Between-Group Difference in } \\
\text { Improvement from Baseline or } \\
\text { P value }\end{array}$} \\
\hline & & & APM & Placebo surgery & \\
\hline Lysholm knee score & 81.8 (75.8 to 87.7$)$ & 86.9 (82.8 to 91.0$)$ & $28.3(21.0$ to 35.5$)$ & 34.1 (28.8 to 39.4$)$ & $-5.9(-14.6$ to 2.8$)$ \\
\hline Pain after exercise & 2.6 (1.7 to 3.5$)$ & $1.9(1.2$ to 2.6$)$ & $3.3(2.2$ to 4.4$)$ & 4.5 (3.7 to 5.3 ) & $-1.2(-2.5$ to 0.2$)$ \\
\hline Improved patients & $27(84.4)$ & $33(89.2)$ & & & $p=0.723$ \\
\hline Treatment-group unblinding & $2(6.3)$ & $1(2.7)$ & & & $p=0.593$ \\
\hline Returned to normal activities & $20(64.5)$ & $29(78.4)$ & & & $p=0.279$ \\
\hline Mechanical symptoms & $11(34.4)$ & $11(29.7)$ & & & $p=0.797$ \\
\hline At least one positive meniscal test & $14(43.8)$ & $14(37.8)$ & & & $p=0.633$ \\
\hline
\end{tabular}

One patient missing return to activity in APM group ( $n=31)$. p Values for interaction (randomisation and mechanical symptoms) were $0.113,0.268$ and 0.097 for the change in WOMET score, Lysholm knee score and pain after exercise, respectively.

APM, arthroscopic partial meniscectomy; WOMET, Western Ontario Meniscal Evaluation Tool.

designed as an efficacy trial to test the therapeutic potential of APM. Accordingly, we recruited a sample that potentially would have an 'optimal response' to APM (medial meniscus tear, no OA). Such patients are rare to find among ordinary patients with a degenerative meniscus tear. This explains the lengthy recruitment period (4 years) despite five high-volume centres, but given our finding of lack of efficacy, this methodological choice actually increases rather than diminishes - the generalisability of our study.

Some have criticised the FIDELITY trial for recruiting patients with symptoms that were not attributable to a meniscal tear, ${ }^{25}$ yet our subjects' eligibility was confirmed by both MRI and arthroscopy. APM is typically advocated for patients with knee symptoms in whom a tear is confirmed by MRI, particularly those without concomitant knee osteoarthritis. ${ }^{47}$ Increasing evidence, however, suggests that a degenerative meniscal tear may be an early sign of knee osteoarthritis rather than a separate clinical problem that causes symptoms. ${ }^{48-50}$ Moreover, specific meniscal pathology and other structural joint pathologies found at meniscal surgery were not associated with preoperative self-reported pain and function in patients with meniscal tears. ${ }^{51}$ We interpret our findings as supportive of the idea that degenerative meniscus tear does not cause specific symptoms even in knees without osteoarthritis. ${ }^{52}$

We are also aware of the limitations related to post hoc subgroup analyses ${ }^{53}$ : the number of participants in our subgroups was small, the analyses were not planned a priori and there was no formal power calculation. However, as patients with mechanical symptoms and with unstable tear have been-and still are-widely

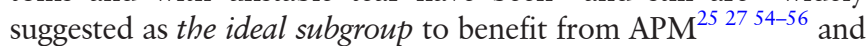
the hypothesis is backed by a credible biological rationale, we felt that our analyses were of high clinical relevance. ${ }^{53}$

We set out to address a few apparent gaps in the existing evidence base regarding arthroscopic surgery for patients with knee pain and degenerative meniscus tear/knee disease. First, although a 24-month follow-up is a commonly held 'minimal requirement' for any procedure in orthopaedics, only three ${ }^{195758}$ of the eight previous RCTs on this topic have followed-up patients longer than 12 months. Our 24-month data show that most of the improvement observed with both APM and placebo surgery was evident already at 6 months after surgery and the extended follow-up did not have an effect on our primary finding. ${ }^{29}$ Second, many authors and organisations

Table 5 Primary and secondary outcomes at 24-month follow-up for the subgroup of patients with unstable meniscus tear. Values are means with $95 \%$ Cls and numbers (percentage)

\begin{tabular}{|c|c|c|c|c|c|}
\hline \multirow[b]{2}{*}{ Primary outcomes } & \multirow[t]{2}{*}{ APM $(n=34)$} & \multirow[t]{2}{*}{$\begin{array}{l}\text { Placebo surgery } \\
(n=39)\end{array}$} & \multicolumn{2}{|c|}{ Improvement from baseline (or $24 \mathrm{mo}$ ) } & \multirow[t]{2}{*}{$\begin{array}{l}\text { Between-Group Difference in } \\
\text { Improvement from Baseline or } P \\
\text { value }\end{array}$} \\
\hline & & & APM & Placebo surgery & \\
\hline Lysholm knee score & 84.5 (78.7 to 90.3$)$ & 86.7 (83.2 to 90.3$)$ & 23.4 (16.7 to 30.2$)$ & 27.5 (22.6 to 32.4$)$ & $-4.0(-12.1$ to 4.0$)$ \\
\hline Pain after exercise & 2.2 (1.4 to 3.0$)$ & $2.2(1.5$ to 3.0$)$ & 3.5 (2.6 to 4.4$)$ & 4.1 (3.2 to 4.9$)$ & $-0.6(-1.8$ to 0.6$)$ \\
\hline \multicolumn{6}{|l|}{ Secondary outcomes } \\
\hline Satisfied patients & $26(76.5 \%)$ & $31(79.5 \%)$ & & & $p=0.784$ \\
\hline Improved patients & $30(88.2 \%)$ & $35(89.7 \%)$ & & & $\mathrm{p}=1.000$ \\
\hline Returned to normal activities & $23(67.6 \%)$ & $30(76.9 \%)$ & & & $\mathrm{p}=0.436$ \\
\hline Mechanical symptoms & $8(23.5)$ & $10(25.6)$ & & & $p=1.000$ \\
\hline At least one positive meniscal test & $10(29.4)$ & $13(33.3)$ & & & $\mathrm{p}=0.803$ \\
\hline
\end{tabular}

Two patients lost to follow-up, both in placebo-surgery group. p Values for interaction (randomisation and unstable tear) were $0.701,0.754$ and 0.623 for the change in W0MET score, Lysholm knee score and pain after exercise, respectively.

APM, arthroscopic partial meniscectomy; WOMET, Western Ontario Meniscal Evaluation Tool. 
advocate APM for patients 'unresponsive to conservative treatment', ${ }^{12-16}$ a strategy based on the previous unblinded trials. ${ }^{19-21}$ These trials showed that about $30 \%$ of participants initially allocated to conservative treatment have opted to crossover to surgery due to persisting symptoms. Although such behaviour is intuitively rational, it should be recalled that when patients are told of the possibility of surgical treatment but are allocated to conservative care, this so-called 'failed opportunity' may drive patients to seek surgery if symptoms persist. ${ }^{42}$ In our blinded trial, the frequency of unblinding of the treatment-group allocation due to persisting symptoms was clearly lower than in the previous-unblindedstudies and we found no difference between our two treatment groups. Our data thus highlight the vital importance of proper blinding of study participants in surgical RCTs. Considering the rationale to carry out APM on those having failed previous conservative treatment further, a recent study comparing exercise therapy to APM alone (with no postoperative rehabilitation) showed that although $19 \%$ of participants allocated to exercise therapy crossed over to surgery during the 2-year follow-up, APM did not result in any additional benefit for them. ${ }^{58}$

Another widely held assertion is that the presence of mechanical symptoms (sensation of knee catching or locking) represents a valid indication for arthroscopic surgery. ${ }^{25-2759}$ This is premised on a rationale that mechanical symptoms are caused by a joint structure lodging between the gliding articular surfaces. Our recently published secondary analysis (1-year follow-up of this trial) showed that resection of a torn meniscus has no added benefit over placebo surgery in relieving knee catching or occasional locking. ${ }^{60}$ The findings of this 2-year extension corroborate our previous findings. The absence of an effect of APM on patients with mechanical symptoms is also supported by previous subgroup analyses of controlled trials ${ }^{2161}$ and our own recent prospective cohort study of 900 consecutive patients undergoing APM. ${ }^{62}$ With respect to the present data, patients with a true locked knee (unable to extend their knee fully) were excluded from the FIDELITY and thus some caution may be warranted in the interpretation of our current findings. Finally, meniscus tear morphology is often asserted to explain the success of APM, ${ }^{17286364}$ but our data fail to support such notion.

In conclusion, the results of this randomised, placebo-controlled trial with 24 months follow-up show that APM provides no significant benefit over placebo surgery in patients with a degenerative meniscal tear and no knee osteoarthritis. These results support the evolving consensus that degenerative meniscus tear represents an (early) sign of knee osteoarthritis, rather than a clinical entity on its own, and accordingly, caution should be exercised in referring patients with knee pain and suspicion of a degenerative meniscal tear to MRI examination or APM, even after a failed attempt of conservative treatment.

\section{Unanswered questions and future research}

Arthroscopic surgery for knee pain in middle-aged and older patients is one of the most rigorously studied orthopaedic procedures. The evidence base shows very consistently that APM offers no benefit over conservative treatment or placebo surgery. ${ }^{65}$ Still, hundreds of thousands of procedures are performed worldwide each year. Given the mounting evidence, anyone still advocating APMs should promptly launch methodologically rigorous, practical, real-world trial(s) embedded in the flow of practice to prove that APM truly works in the asserted subgroups of patients.

\section{Author affiliations}

'Department of Orthopedics and Traumatology, Hatanpää Hospital, Tampere, Finland
${ }^{2}$ Department of Orthopedics and Traumatology, Helsinki University Hospital, Helsinki, Finland

${ }^{3}$ Center for Health and Social Economics, National Institute for Health and Welfare, Helsinki, Finland

${ }^{4}$ Department of Orthopedics and Traumatology, Turku University Hospital, Turku, Finland

${ }^{5}$ Department of Orthopedics and Traumatology, Kuopio University Hospital, Kuopio, Finland

${ }^{6}$ Department of Orthopedics and Traumatology, Central Finland Central Hospital, Jyväskylä, Finland

${ }^{7}$ Arthroscopic and Sports Medicine Center Pohjola Sairaala, Helsinki, Finland ${ }^{8}$ Department of Orthopedics and Traumatology, Tampere University Hospital, Tampere, Finland

${ }^{9}$ Department of Orthopaedics and Traumatology, Helsinki University, Töölö Hospital, Helsinki, Finland

Acknowledgements We thank the patients for their participation. We would like to thank research nurses Marja-Liisa Sutinen, Sari Karesvuori, Pekka Karppi, SaaraMaija Hinkkanen, Johanna Koivistoinen, Kirsi Saarioja, Elina Jalava, Ina Fagerlund and Marketta Rautanen for their vital role in the implementation of the study.

Contributors The Finnish Degenerative Meniscal Lesion Study (FIDELITY) trial (patient enrolment and execution of follow-up assessments in 2007-2015) is carried out by the FIDELITY Investigators. Conception and design: RS, MP, AM and TLNJ. Analysis and interpretation of the data: RS and TLNJ. Drafting of the article: RS and TLNJ. Critical revision of the article for important intellectual content and final approval: all authors. Ensuring the accuracy of the work: RS and TLNJ. Obtaining of funding: TLNJ. All authors had full access to all of the data in the study and can take responsibility for the integrity of the data and the accuracy of the data analysis.

Funding This study was supported by the Jane and Aatos Erkko Foundation, the Sigrid Juselius Foundation, the State funding for university-level health research (Tampere and Helsinki University Hospitals), the Social Insurance Institution of Finland (KELA) and the Academy of Finland. Dr Sihvonen is supported also by The Finnish Medical Foundation and Orion-Pharmos Research Foundation. The funding sources had no role in in the collection, analysis and interpretation of data; in the writing of the report and in the decision to submit the article for publication.

Competing interests All authors have completed the ICMJE uniform disclosure form at www.icmje.org/coi_disclosure.pdf and declare: no support from any organisation for the submitted work; no financial relationships with any organisations that might have an interest in the submitted work in the previous three years; no other relationships or activities that could appear to have influenced the submitted work.

Provenance and peer review Not commissioned; externally peer reviewed.

Data sharing statement Given that the informed consent forms of the Finnish Degenerative Meniscal Lesion Study trial did not include a provision for data sharing (trial launched in 2007), the full dataset cannot be shared due to a potential breach of the Finnish Personal Data Act. Scientists with a specific question regarding the trial data are encouraged to contact the corresponding author (TLNJ).

Open Access This is an Open Access article distributed in accordance with the Creative Commons Attribution Non Commercial (CC BY-NC 4.0) license, which permits others to distribute, remix, adapt, build upon this work non-commercially, and license their derivative works on different terms, provided the original work is properly cited and the use is non-commercial. See: http://creativecommons.org/ licenses/by-nc/4.0/

(c) Article author(s) (or their employer(s) unless otherwise stated in the text of the article) 2018. All rights reserved. No commercial use is permitted unless otherwise expressly granted.

\section{REFERENCES}

1 Cullen KA, Hall MJ, Golosinskiy A. Ambulatory surgery in the United States, 2006. Nat Health Stat Report 2009;11:1-25.

2 Abrams GD, Frank RM, Gupta AK, et al. Trends in meniscus repair and meniscectomy in the United States, 2005-2011. Am J Sports Med 2013;41:2333-9.

3 Thorlund JB, Hare KB, Lohmander LS. Large increase in arthroscopic meniscus surgery in the middle-aged and older population in Denmark from 2000 to 2011. Acta Orthop 2014;85:287-92

$4 \mathrm{Kim} \mathrm{S}$, Bosque J, Meehan JP, et al. Increase in outpatient knee arthroscopy in the United States: a comparison of National surveys of ambulatory surgery, 1996 and 2006. J Bone Joint Surg Am 2011:93:994-1000.

5 Montgomery SR, Zhang A, Ngo SS, et al. Cross-sectional analysis of trends in meniscectomy and meniscus repair. Orthopedics 2013:36:e1007-e1013.

6 Khan M, Evaniew N, Bedi A, et al. Arthroscopic surgery for degenerative tears of the meniscus: a systematic review and meta-analysis. CMAJ 2014;186:1057-64.

7 Thorlund JB, Juhl CB, Roos EM, et al. Arthroscopic surgery for degenerative knee: systematic review and meta-analysis of benefits and harms. BMJ 2015;350:h2747. 
8 Lamplot JD, Brophy RH. The role for arthroscopic partial meniscectomy in knees with degenerative changes: a systematic review. Bone Joint J 2016;98-B:934-8.

9 Monk P, Garfjeld Roberts P, Palmer AJ, et al. The Urgent Need for evidence in arthroscopic meniscal surgery: a systematic review of the evidence for Operative Management of Meniscal Tears. Am J Sports Med 2016.

10 van de Graaf VA, Wolterbeek N, Mutsaerts EL, et al. Arthroscopic partial meniscectomy or conservative treatment for Nonobstructive Meniscal Tears: a systematic review and Meta-analysis of Randomized Controlled Trials. Arthroscopy 2016;32:1855-65.

11 Katz JN, Jones MH. Treatment of meniscal tear: the more we learn, the less we Know. Ann Intern Med 2016;164:503.

12 Howell R, Kumar NS, Patel N, et al. Degenerative meniscus: Pathogenesis, diagnosis, and treatment options. World J Orthop 2014;5:597-602.

13 Mordecai SC, Al-Hadithy N, Ware HE, et al. Treatment of meniscal tears: an evidence based approach. World J Orthop 2014:5:233-41.

14 Carr AJ, Price AJ, Glyn-Jones S, et al. Advances in arthroscopy-indications and therapeutic applications. Nat Rev Rheumatol 2015:11:77-85.

15 Price A, Beard D. Arthroscopy for degenerate meniscal tears of the knee. BMJ 2014;348:g2382.

16 Katz JN, Losina E. Arthroscopic partial meniscectomy for degenerative tears: where do we stand? Osteoarthritis Cartilage 2014;22:1749-51.

17 El Ghazaly SA, Rahman AA, Yusry AH, et al. Arthroscopic partial meniscectomy is superior to physical rehabilitation in the management of symptomatic unstable meniscal tears. Int Orthop 2015:39:769-75.

18 Hutt JR, Craik J, Phadnis J, et al. Arthroscopy for mechanical symptoms in osteoarthritis: a cost-effective procedure. Knee Surg Sports Traumatol Arthrosc 2015;23:3545-9.

19 Herrlin SV, Wange PO, Lapidus G, et al. Is arthroscopic surgery beneficial in treating non-traumatic, degenerative medial meniscal tears? A five year follow-up. Knee Surg Sports Traumatol Arthrosc 2013;21:358-64.

20 Katz JN, Brophy RH, Chaisson CE, et al. Surgery versus physical therapy for a meniscal tear and osteoarthritis. N Eng/ J Med 2013;368:1675-84.

21 Gauffin $H$, Tagesson S, Meunier A, et al. Knee arthroscopic surgery is beneficial to middle-aged patients with meniscal symptoms: a prospective, randomised, singleblinded study. Osteoarthritis Cartilage 2014;22:1808-16.

22 Katz JN, Wright J, Spindler KP, et al. Predictors and outcomes of Crossover to surgery from physical therapy for Meniscal Tear and Osteoarthritis: a Randomized Trial comparing physical therapy and surgery. J Bone Joint Surg Am 2016;98:1890-6.

23 Buchbinder R. Meniscectomy in patients with knee osteoarthritis and a meniscal tear? N Engl J Med 2013;368:1740-1.

24 Katz JN. Surgery for lumbar spinal stenosis: informed patient preferences should weigh heavily. Ann Intern Med 2015;162:518-9.

25 Krych AJ, Carey JL, Marx RG, et al. Does arthroscopic knee surgery work? Arthroscopy 2014:30:544-5

26 Stuart MJ, Lubowitz JH. What, if any, are the indications for arthroscopic debridement of the osteoarthritic knee? Arthroscopy 2006;22:238-9.

27 Jevsevar DS, Yates AJ, Sanders JO. Arthroscopic partial meniscectomy for degenerative meniscal tear. N Engl J Med 2014;370:1260.

28 Sadoghi P, Gomoll AH. New England journal of medicine article evaluating the usefulness of meniscectomy is flawed. Arthroscopy 2014;30:659-60.

29 Sihvonen R, Paavola M, Malmivaara A, et al. Arthroscopic partial meniscectomy versus sham surgery for a degenerative meniscal tear. N Engl J Med 2013;369:2515-24.

30 Altman R, Asch E, Bloch D, et al. Development of criteria for the classification and reporting of osteoarthritis. classification of osteoarthritis of the knee. diagnostic and therapeutic Criteria Committee of the american Rheumatism Association. Arthritis Rheum 1986;29:1039-49.

31 Kellgren JH, Lawrence JS. Radiological assessment of osteo-arthrosis. Ann Rheum Dis 1957;16:494-502.

32 Solomon DH, Simel DL, Bates DW, et al. The rational clinical examination. does this patient have a torn Meniscus or ligament of the knee? value of the physical examination. JAMA 2001;286:1610-20.

33 McMurray TP. The semilunar cartilages. Br J Surg 1942;29:407-14.

34 Sihvonen R, Paavola M, Malmivaara A, et al. Finnish degenerative meniscal lesion study (FIDELITY): a protocol for a randomised, placebo surgery controlled trial on the efficacy of arthroscopic partial meniscectomy for patients with degenerative Meniscus injury with a novel 'RCT within-a-cohort' study design. BMJ Open 2013;3:e002510.

35 Brittberg $M$, Winalski CS. Evaluation of cartilage injuries and repair. J Bone Joint Surg Am 2003;85-A(Suppl 2):58-69.

36 Anderson AF, Irrgang JJ, Dunn W, et al. Interobserver reliability of the International Society of Arthroscopy, Knee Surgery and Orthopaedic Sports Medicine (ISAKOS) classification of meniscal tears. Am J Sports Med 2011;39:926-32.

37 Kirkley A, Griffin S, Whelan D. The development and validation of a quality of lifemeasurement tool for patients with meniscal pathology: the Western Ontario Meniscal Evaluation Tool (WOMET). Clin J Sport Med 2007:17:349-56.
38 Sihvonen $\mathrm{R}$, Jarvela $\mathrm{T}$, Aho $\mathrm{H}$, et al. Validation of the Western Ontario Meniscal evaluation Tool (WOMET), a Meniscal pathology-specific Quality-of-Life index, for patients with a Degenerative Meniscus tear. J Bone Joint Surg Am 2012;94:e65-1-8.

39 Tegner Y, Lysholm J. Rating systems in the evaluation of knee ligament injuries. Clin Orthop Relat Res 1985;198:43-9.

40 Briggs KK, Kocher MS, Rodkey WG, et al. Reliability, validity, and responsiveness of the Lysholm knee score and Tegner activity scale for patients with meniscal injury of the knee. J Bone Joint Surg Am 2006;88:698-705.

41 Hamilton DF, Lane JV, Gaston P, et al. What determines patient satisfaction with surgery? A prospective cohort study of 4709 patients following total joint replacement. BMJ Open 2013;3:e002525

42 Dowrick AS, Bhandari M. Ethical issues in the design of randomized trials: to sham or not to sham. J Bone Joint Surg Am 2012;94(Suppl 1):7-10.

$43 \mathrm{Kim}$ JR, Kim BG, Kim JW, et al. Traumatic and non-traumatic isolated horizontal meniscal tears of the knee in patients less than 40 years of age. Eur J Orthop Surg Traumatol 2013;23:589-93.

44 Thorlund JB, Englund M, Christensen R, et al. Patient reported outcomes in patients undergoing arthroscopic partial meniscectomy for traumatic or degenerative meniscal tears: comparative prospective cohort study. BMJ 2017;356:356.

45 Elattrache N, Lattermann C, Hannon M, et al. New England journal of medicine article evaluating the usefulness of meniscectomy is flawed. Arthroscopy 2014;30:542-3.

46 Rossi MJ, D'Agostino RB, Provencher MT, et al. Could the New England journal of medicine be biased against Arthroscopic knee surgery? Arthroscopy 2014;30:536-7.

47 Lyman S, Oh LS, Reinhardt KR, et al. Surgical decision making for arthroscopic partial meniscectomy in patients aged over 40 years. Arthroscopy 2012;28:492-501.

48 Englund M, Guermazi A, Roemer FW, et al. Meniscal tear in knees without surgery and the development of radiographic osteoarthritis among middle-aged and elderly persons: the Multicenter Osteoarthritis Study. Arthritis Rheum 2009;60:831-9.

49 Badlani JT, Borrero C, Golla S, et al. The effects of meniscus injury on the development of knee osteoarthritis: data from the osteoarthritis initiative. Am J Sports Med 2013:41:1238-44.

50 Dervin GF, Stiell IG, Wells GA, et al. Physicians' accuracy and interrator reliability for the diagnosis of unstable meniscal tears in patients having osteoarthritis of the knee. Can J Surg 2001:44:267-74.

51 Tornbjerg SM, Nissen N, Englund M, et al. Structural pathology is not related to patient-reported pain and function in patients undergoing meniscal surgery. $\mathrm{Br}$ J Sports Med 2017;51:525-30.

52 Englund M, Niu J, Guermazi A, et al. Effect of meniscal damage on the development of frequent knee pain, aching, or stiffness. Arthritis Rheum 2007; 56:4048-54.

53 Sun $X$, loannidis JP, Agoritsas T, et al. How to use a subgroup analysis: users' guide to the medical literature. JAMA 2014;311:405-11.

54 Conaghan PG, Dickson J, Grant RL, et al. Care and management of osteoarthritis in adults: summary of NICE guidance. BMJ 2008;336:502-3.

55 Zhang W, Moskowitz RW, Nuki G, et al. OARSI recommendations for the management of hip and knee osteoarthritis, part I: critical appraisal of existing treatment guidelines and systematic review of current research evidence. Osteoarthritis Cartilage 2007; 15:981-1000.

56 Krych AJ, Stuart MJ, Levy BA. Arthroscopic partial meniscectomy for degenerative meniscal tear. N Engl J Med 2014;370:1259.

57 Yim JH, Seon JK, Song EK, et al. A comparative study of meniscectomy and nonoperative treatment for degenerative horizontal tears of the medial meniscus. Am J Sports Med 2013;41:1565-70.

58 Kise NJ, Risberg MA, Stensrud S, et al. Exercise therapy versus arthroscopic partial meniscectomy for degenerative meniscal tear in middle aged patients: randomised controlled trial with two year follow-up. BMJ 2016;354:i3740.

59 NICE. Osteoarthritis: care and Management in adults. London: National Institute for Health and Care Excellence (UK), 2014.

60 Sihvonen R, Englund M, Turkiewicz A, et al. Mechanical symptoms and arthroscopic partial meniscectomy in patients with degenerative Meniscus tear: a secondary analysis of a Randomized Trial. Ann Intern Med 2016;164:449-55.

61 Kirkley A, Birmingham TB, Litchfield RB, et al. A randomized trial of arthroscopic surgery for osteoarthritis of the knee. N Engl J Med 2008;359:1097-107.

62 Sihvonen R, Englund M, Turkiewicz A, et al. Mechanical symptoms as an indication for knee arthroscopy in patients with degenerative Meniscus tear: a prospective cohort study. Osteoarthritis Cartilage 2016;24:1367-75

63 Richmond JC. Surgery for osteoarthritis of the knee. Rheum Dis Clin North Am 2013;39:203-11.

64 Scillia AJ, McDermott JD, Issa K, et al. Arthroscopic partial meniscectomy for Meniscal Tears: a review and commentary on a study by NEJM. J Knee Surg 2016;29:387-90.

65 Roos EM, Thorlund JB. It is time to stop meniscectomy. Br J Sports Med 2017:51:490-1. 